\title{
Effects of Cold Water Application on Isokinetic Strength of the Plantar Flexors
}

\author{
By: Carl G. Mattacola, MEd, AT, $\mathrm{C}^{*}$ and David H. Perrin, PhD, AT, $\mathrm{C}^{\dagger}$ \\ Mattacola, C.G., \& Perrin, D.H. (1993). Effects of cold water application on isokinetic strength \\ of the plantar flexors. Isokinetics and Exercise Science, 3, 152-159.
}

\section{***Note: Figures may be missing for this format of the document}

\begin{abstract}
:
Cold (cryotherapy) is commonly applied to an athlete immediately before and/or after sports participation. The purpose of this study was to determine the effect of cold water submersion (CWS) on isokinetic strength of the plantar flexor muscle group. Eleven women and five men (mean age 22.1 years, height $170.8 \mathrm{~cm}$, weight $64.5 \mathrm{~kg}$ ) with no history of ankle joint pathology were tested for peak torque, average power, and total work of the dominant foot at $60 \mathrm{deg} / \mathrm{sec}$ with a Cybex II isokinetic dynamometer. Before isokinetic testing subjects were randomly assigned to either CWS or an inactive rest period (RP). Subjects returned 1 week later to receive the opposite treatment and undergo isokinetic testing. The CWS consisted of placing the leg in a $15^{\circ} \mathrm{C}$ tub of water for 20 minutes. The RP consisted of remaining seated for a 20 -minute period. Paired $t$ tests were computed to determine if any differences existed in peak torque, average power, and total work between the CWS and RP conditions. Results indicated concentric isokinetic strength values were lower after CWS for peak torque, average power and total work of the plantar flexor muscle group. These findings indicate that concentric isokinetic torque, power, and work of the plantar flexor muscle group are reduced immediately after CWS. Further research should be undertaken to determine the length of time isokinetic output is reduced before returning to normal responses after CWS is present.
\end{abstract}

\section{INTRODUCTION}

The local application of cold is known to decrease temperatures to the applied area, ${ }^{1-6,9,11,17}$ cause a vasoconstriction of blood vessels as the body attempts to conserve and prevent heat loss, ${ }^{15}$ and cause a decrease in muscular temperature. ${ }^{1,7,9,15}$ The application of cold has also been shown to produce a slowing of motor nerve conduction velocity ${ }^{9}$ that results in an inefficiency of the musculotendinous unit.

The application of cold produces varied effects on muscular strength. The literature that examines the effects of cold application on strength has focused primarily on isometric assessment. In some instances, an increase in strength has been reported' $10,12,16,17$ and $i_{n}$ some instances a decrease has been seen. ${ }^{2}{ }^{4}$ The availability of research involving the effects of cold application on isokinetic muscular strength is limited.? Isokinetic resistance enables accurate and reliable quantification of strength. As such, additional research is needed to determine the effects of the local application of cold on human muscular performance. The purpose of this study was to test the effect of local cooling on isokinetic peak torque, average power, and total work of the human ankle plantar flexors.

\section{METHODS AND MATERIALS}

\section{Subjects}

\footnotetext{
* Doctoral Student in Sports Medicine, University of Virginia, Charlottesville, VA 22901.

${ }^{\dagger}$ Associate Professor and Director, Sports Medicine/Athletic Training Research Laboratory and Graduate Athletic Training Education, University of Virginia, Charlottesville, VA 22901.
} 
Sixteen subjects [11 women, five men $(\mathrm{age}=22.1$ years, height $=170.8 \mathrm{~cm}$, weight $=64.5 \mathrm{~kg})$ ] not involved in a lower body exercise program were selected to participate in this study. Subjects were screened for history of pathology that might have prevented them from producing a maximum contraction of the plantar flexors and for history of adverse reaction to cold application. Before testing each subject read and signed a consent to participate form that outlined the potential benefits and risks of the study.

After an explanation of the test procedures, subjects were randomly assigned to undergo either a cold water submersion (CWS) or rest period (RP) control condition before an isokinetic assessment. Subjects returned 1 week later for a second testing session in which they underwent the opposite condition before a second isokinetic assessment.

\section{Cold Immersion}

Subjects were placed in an ice immersion of $15^{\circ} \mathrm{C}$ for 20 minutes. The leg was immersed from mid-patella to distal extremity. The temperature of the ice immersion was monitored and adjusted accordingly during the application to maintain the desired temperature. Each subject was instructed to move the foot in circular motions every 2 minutes to prevent a thermal barrier from surrounding the skin.

\section{Isokinetic Assessment}

The Cybex II isokinetic dynamometer (Lumex, Ronkonkoma, NY) was used to measure strength of the plantar flexor muscle group. The setup procedure for the Cybex dynamometer was performed for each subject upon arrival, so that testing could begin as quickly as possible after conclusion of cold application.

Each subject was positioned in a prone position with the knee in a fully extended position, and was stabilized at the waist with a Velcro strap allowing dynamometer alignment. The subjects wore athletic shoes and were instructed to report to the second testing session with the same footwear. Peak torque, average power, and total work of the plantar flexors were tested through a range of motion from 0 to $50 \mathrm{deg}$. The dominant leg was tested and was identified as the leg that the subject would use to kick a ball.

The test protocol included three submaximal and three maximal warm-up repetitions at 60 $\mathrm{deg} / \mathrm{sec}$. After 1 minute of rest, each subject then performed eight maximal repetitions at 60 $\mathrm{deg} / \mathrm{sec}$. Verbal encouragement was provided during the test to facilitate a maximal effort. The Cybex Data Reduction Computer reported peak torque and total work in foot-pounds, and average power in watts. Paired $t$ tests were computed to determine if any differences existed between the cold and control conditions for each of the isokinetic parameters with a level of significance chosen at the 0.05 level.

\section{RESULTS}

The means and standard deviations for peak torque, average power, and total work are presented in Figures 1 and 2. Results indicated isokinetic strength was diminished after CWS for the peak torque $(t=50.3 \mathrm{ft}-1 \mathrm{bs}, \mathrm{p}<0.01)$, average power $(t=45.1 \mathrm{~W}, \mathrm{p}<0.01)$, and total work $(t=224.7 \mathrm{ft}-1 \mathrm{bs}, \mathrm{p}<0.01)$. 


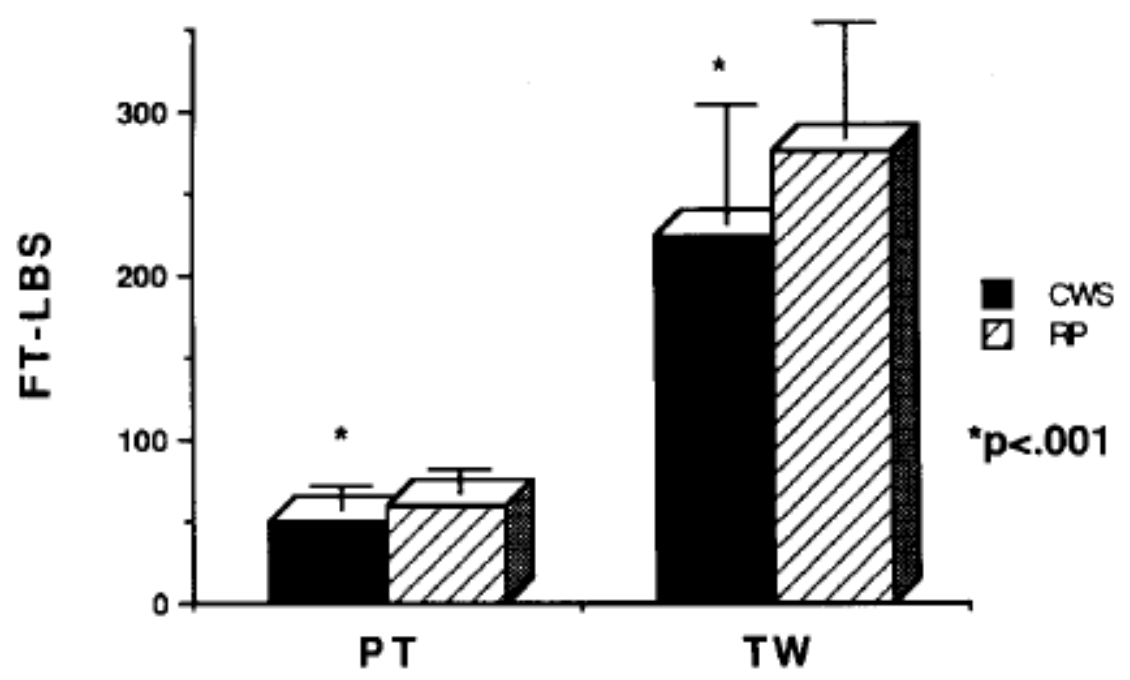

Figure 1 Plantar flexion peak torque and total work.

\section{DISCUSSION}

The application of cold has previously been shown to decrease strength of isometric contractions when strength testing immediately followed the application. ${ }^{2,12,14,16}$ The effect of cold on isokinetic strength has not been examined extensively. We evaluated the effect of a cold water application on isokinetic strength of the plantar flexor group.

The major finding of this study was that isokinetic plantar flexor strength was significantly reduced immediately after CWS. Several studies have examined the effects of cold on isometric strength. ${ }^{2,4,12,14,16,17}$ These studies generally show that strength decreases can be expected immediately after the application of cold to a muscle. However, to date few studies have involved the effects of cold on isokinetic strength,' and as such the research regarding isokinetic testing is still unclear. 
Haymes and Ryder' tested eight subjects for isokinetic torque of the quadriceps muscle group at $30 \mathrm{deg} / \mathrm{sec}, 180 \mathrm{deg} / \mathrm{sec}$, and $300 \mathrm{deg} / \mathrm{sec}$ after cooling of the thigh. Subjects were tested on two different occasions: once while receiving the ice application and again after a no-ice application control condition. They found that cooling of the thigh resulted in nonsignificant decreases in torque at each of the three speeds. Interestingly, they also found no significant difference between total work with and without cooling, and that total work actually increased (nonsignificant) in six of the eight subjects. Haymes and Ryder speculated that the effects of cooling on isokinetic torque are more variable (than isometric testing) and may be related to the diameter of the limb.

The findings of our investigation are in contrast to those of Haymes and Rider in that we found a decrease in isokinetic strength after the application of cold. Any one of several factors may have accounted for these differences. We assessed strength of the plantar flexor muscle group, whereas, Haymes and Rider assessed the quadriceps musculature. The method of cold application in our investigation included total submersion of the body region, whereas Haymes and Rider applied cold by ice bag to a smaller percentage of the muscle group involved. As such, the amount of cooling may have been greater in our study.

The potential clinical implication of our finding is that the application of cold before athletic participation may have a deleterious affect on both injury prevention and performance. As such, caution is recommended, when returning an athlete to competition after the application of cold. Future research should be undertaken to determine how long concentric strength is adversely affected after the application of cold, and if eccentric values are similarly affected.

\section{CONCLUSION}

Results of this study suggest that after cold submersion of $15^{\circ} \mathrm{C}$ for 20 minutes, concentric peak torque, average power, and total work of the plantar flexors is significantly reduced. Further research is needed to determine ideal temperatures and times for specific body regions and to further test the effects of cold application on isokinetic strength.

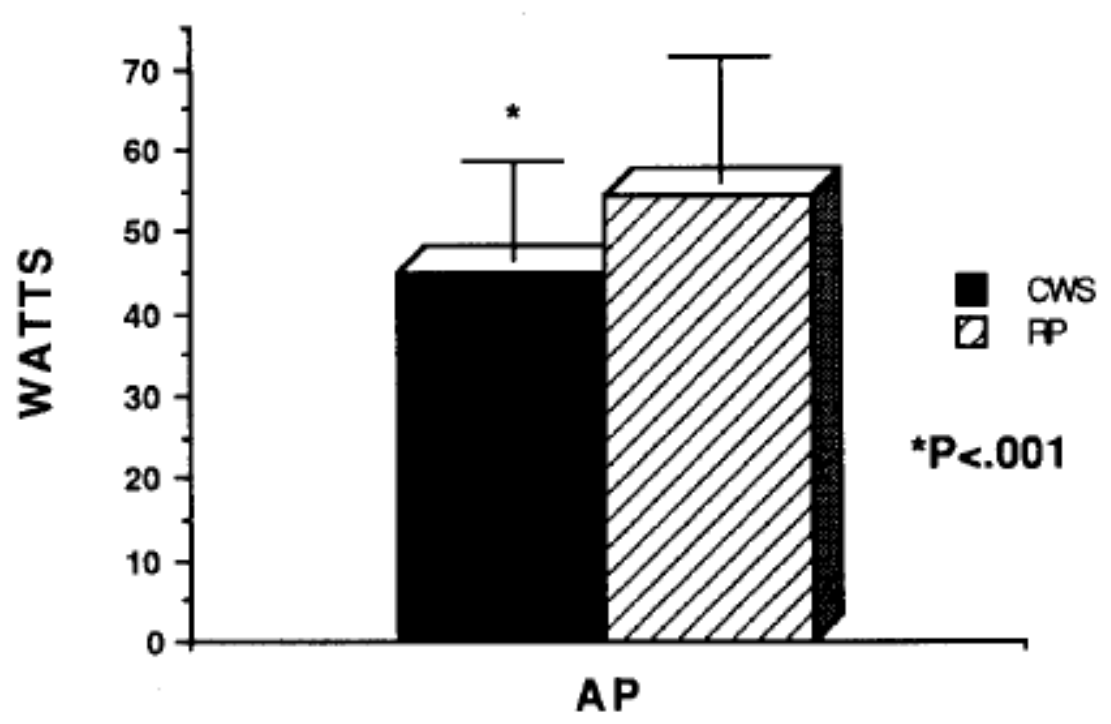

Figure 2 Plantar flexion average power. 


\section{REFERENCES}

1. Abramson DI, Chu LSW, Tuck Jr, Lee SW, Richardson G, Levin M: Effect of tissue temperature and blood flow on motor nerve conduction velocity. JAMA 198:1082$1088,1966$.

2. Barnes W, Larson M: Effects of localized hyper- and hypothermia on maximal isometric grip strength. Am J Phys Med 64:305-314,1985.

3. Cobbald AF, Lewis 0J: Blood flow to the knee joint of the dog: effect of heating, cooling and adrenaline. J Physiol 132:379-383,1956.

4. Coppin EG, Livingstone SD, Kuehn LA: Effects of handgrip strength during arm immersion in a $10^{\circ}$ water bath. Aviat Space Environ Med 49:1322-1326,1978.

5. Eldred E, Lindsley DF, Buchwald JS: The effect of cooling on mammalian muscle spindles. Exp Neurol 2:144-157,1960.

6. Hart DL, Miller L, Stauber W: Effect of cooling on force oscillations during maximal voluntary eccentric exercise. Exp Neurol 90:73-80, Chatanooga, TN, 1985.

7. Haymes EM, Rider RA: Effects of leg cooling in peak isokinetic torque and endurance. Am Corr Ther J 37:109-115,1983.

8. Knight, K. Cryotherapy: theory, technique and physiology, 1st ed,1985.

9. Lowdon BJ, Moore RJ: Temperature changes in muscle during cold therapy and following a sustained contraction. Aust J Sports Med 2:9-12,1977.

10. McGown H: Effects of cold application on maximal isometric contraction. Phys Ther Rev 47:185-192,1967.

11. McMaster W: Cryotherapy. Phys Sports Med 10:112119,1982.

12. Michielli D: The effect of lowered internal muscle temperature on the strength of the elbow flexor. Thesis, Ohio State University, 1961.

13. Michlovitz S: Thermal agents in rehabilitation, 2nd ed, Philadelphia: F.A. Davis, 1982.

14. Oliver RA, Johnson DJ: The effect of cold water baths on posttreatment leg strength. Phys Sport Med 4:67-69, 1976.

15. Oliver RA, Johnson DJ, Wheelhouse WW, Griffen PP: Isometric muscle contraction response during recovery from reduced intramuscular temperature. Arch Phys Med Rehabil 60:126-129,1979.

16. Prentice W: Therapeutic modalities in sports medicine, 2nd ed, St. Louis: Times Mirror/Mosby, 1990.

17. Zankel H: Effect of physical agents on motor conduction velocity of the ulnar nerve. Arch Phys Med Rehabil 12:787-792,1966. 